\title{
A HEGEMONIA DA MÍDIA TELEVISIVA E O ENSINO DE HISTÓRIA
}

Cássia Rita Louro Palha

RESUMO:

Pensarmos o ensino de História hoje é, antes de tudo, ampliarmos nossos horizontes para as múltiplas instâncias através das quais a educação se materializa na tessitura social, de forma muitas das vezes bem mais socializadora que o ensino institucionalizado, como o caso da mídia televisiva. O presente artigo visa abordar a pedagogia mediática televisiva encuanto poderosa formadora de opinião das sociedades modernas e das implicações desse excrcício de hegemonia frente à formação de nossos alunos c à construção do conhecimento histórico.

UNITERMOS: mídia televisiva, hegemonia, ensino de História.

Televisão! Acreditamos haver um consenso sobre a necessidade de trabalharmos em nossas salas de aula com esse já hanalizado meio de comunicação, para além da dimensão de um simples recurso didático, explorando-o enquanto documento histórico. Contudo, nesse trabalho de crítica documental parecenos escapar por entre os dedos a real dimensão do papel da mídia televisiva nas relações de poder estahelecidas nas sociedades modernas.

A televisão não é simplesmente mais um elo integrante do sistema mediático, ou mais um rico documento a ser digerido em

Ciraduada em História pela UFJF, Mestre em Educação pela UFF, atualmente faz parte do corpo docente da Universidade Presidente Antonio Carlos na área de Ensino e Pesquisa de História e da Universidade Estácio de Sá, onde leciona História da Educação. 
nossas salas de aula, nos dando aquela sensação do dever bem cumprido frente as necessidades dos novos objetos da História.

Se do ponto de vista da tecnologia a televisão se apresenta como "coisal do passado», frente por exemplo à informatização em larga escala ou ao progressivo processo da robotização, consideradas "coisas do presente"- avanços que diga-se de passagem tem contribuído para a exclusão de trabalhadores de seus postos de trabalho e para o realinhamento dos países periféricos sob renovados estatutos de submissão, relegando comunidades inteiras a novos regimes de apartheid - enquanto poderosa "educadora de massas" a mídia televisiva representa neste contexto desenvolvimentista-excludente, um dos grandes alicerces da manutenção do "status quo", produzindo através da reconstrução do real um direcionamento tal nas "mentalidades", capaz de esterilizar as diferenças e a própria exploração.

Assim, falarmos de mídia é antes de tudo posicionarmos sua função à partir das relaçêes de poder, dentro de um exercício constante pela busca de hegemomial no seio de nossas sociedades. Segundo Ianni, ela pode ser considerada um verdadeiro "Príncipe eletrônico", um intelectual colctivo e orgânico das frações dominantes:

\footnotetext{
' Hegemonia apui utilizada na concepção gramsciana que a entende enquanto capacidade de direção de determinadas fraçóes sociais sobre outras, ou ainda, aquela fraçäo social que se apresenta à demais como aquela que representa e atende aros interesses e valores de toda uma sociedade, obtendo o consenso voluntírio e a anuência espontânea e garantindo assim, a unidade do bloco social, que embora năo seja homogêneo, se mantém articulado e coeso (cf. GRAMSCI, A .Concépçấo Dialética da História. Rio de Janeiro: Civilização Brasilcira, 1995).

Em Ciramsci, os intelectuais podem ser vistos como funcionários da superestrutura, mantenedores da hegemonia social e do governo político, garantindo o consenso das grandes massas no conjunto da vida social (cf. (IRAMSCI, 1995).
} 
O príncipe eletrônico é entidade nebulosa e ativa, presente e invisível, predominante e ubíqua, permeando continuamente todos os níveis da sociedade, em âmbito local, nacional, regional e mundial. Éo intelectual coletivo e orgânico das estruturus e blocos de poder presentes, predominantes e atuantes em escala nacional, regional e mundial, sempre em conformidade com os diferentes contextos sócio-culturais e político-econômicos desenhados no novo mapa do mundo' (grifo nosso).

Dentro do universo mediático, a televisão é sem dúvida a instância mais abrangente e de maior impacto junto às bases sociais em nosso país. Os anos da ditadura militar foram decisivos nesse sentido, servindo de invólucro para a aceleração de um sucateamento progressivo de nossas escolas públicas, enquanto geravam por outro lado a hipertrofia dos meios de comunicação.

Apesar de ter surgido no Brasil na década de $1950^{4}$, sob um ainda incipiente mercado urbano-industrial, a TV a partir dos anos 60, ganha um impulso único dentro da conjuntura política-econômica constituindo-se em um poder fundamental

'IANNI, Octávio. O Príncipe Eletrônico. Revista Primeira Versäo, Campinas: IFCH/LNICAMP, n.78, 1998.

+ As primeiras emissoras de TV foram inauguradas no início dos ano 50 (setembro de 1950, TV Tupi de São Paulo, canal 3; em janeiro de 1951, TV Tupi do Rio de Janeiro, canal 6). As verhas publicitárias dividiram-se majoritariamente cntre jornais, revistas e emissoras de rádio. Neste momento, a TV implantou-se como uma mera e curiosa inovação tecnológica destinada às elites. Segundo Sodré, já na segunda metade da década, o ufanismo desenvolvimentista da era JK fomentou a inciativa dos empresários e a proliferação das emissoras (TV Paulista, TV Recorde, TV Continental, TV-Rio). Nada mais expressivo nesse momente que a figura de Assis Chauteaubriand, o primeiro capitão da indústria do jornalismo hrasileiro, yue indiferente ao incipiente mercado, comprou de uma única vez nove estações nos Estados Unidos paráuma realidade cue não chegava a 250 mil receptores em todo o país. Um panorama que começou a transformar-se a partir da década de $60 \mathrm{com}$ a ampliação do consumo industrial, apesar dos índices inflacionários da economia. (haviam 15 estações de TV nas capitais). A televisão começou então a assumir seu caráter comercial, disputando

História \& Ensino, Londrina, v. 7, p. 9-22, out. 2001 
no processo de acumulação do capital na medida em que, através de seu discurso ideológico, garantia a reprodução das condições produtivas dominantes. Junto com a expansão da demanda de bens e serviços de luxo, proporcionada pela ampliação do crédito ao consumidor durante o "milagre econômico", a TV brasileira assistiu ao seu boom histórico de vendas, assim como firmou as bases de sua interferência "teleguiada" na vida política brasileira. Neste cenário, o Estado ao mesmo tempo que descaracterizava e reprimia as organizações populares, valia-se do poder mediático para relacionar-se diretamente com indivíduos atomizados, com a televisão cada vez mais se consolidando enquanto árbitro por excelência do acesso à existência social e política das maiorias.

No Brasil "democrático", a interferência da mídia televisiva continua se superando e administrando sua hegemonia no campo das mentalidades. Associada ao desenvolvimento de uma tecnologia canda vez mais avançada, sua influência progressiva nas formas de participação política dos cidadãos é crivada seja pela "criação de uma realidade social despolitizada, seja pela estimulação de técnicas plebiscitárias de sondagem da opinião pública ou então pela simples conversão das campanhas eleitorais em táticas mercadológicas."

Ambas dimensões percorrem a questão da "reprodução" do vivido, de uma pretensa reconstrução mediática da própria História. Nas palavras do historiador Pierre Nora:

verbas publicitárias na busca de maior audiência. A TV pioneira nesse sentido foi a Excelsior yue acabou por abrir espaço para a afirmação da Rede Globo, o que marcou de certa forma o início de um sistema televisivo brasileiro ou ainda, o início de uma indústria da comnnicação televisiva. A esse respeito ver: SOI)RÉ, Muniz. ( ) mumopólio da fala: função e linguagem da televisão no Brasil. 6. ed. P'etrópolis: Vozes, 1984.

¿SOIDRE, Muniz. Reinventando a cultura: a comunicação e seus produtos. Petrópolis: Vozes, 1996. p. 72. 
[...] nenhuma época se viu como a nossa, viver o seu presente como já possuído de um sentido histórico. [...] É aos mass media que se deve o reaparecimento do monopólio da História. De agora em diante esse monopólio thes pertence. Nas sociedades contemporâneas, é por intermédio deles e somente por eles que o acontecimento marca sua presença e não nos pode evitart.

Essa construção mediática do sentido histórico de um presente, que em frações de segundos é capaz de chegar aos lares de milhões de pessoas, selecionando, registrando e interpretando o vivido, mudou completamente, a noção que tínhamos de "acontecimento".

Nora nos dá o tom das mudanças do que hoje é veiculado como acontecimento: "no interior de sua categoria bem marcada, () acontecimento se faz assinalar por sua importância, a novidade da mensagem, tanto menos indiscreto quanto menos hanal". 'Em outras palavras, você pode estar sentado em sua poltrona assistindo $T V$ e de repente, a notícia de cinco minutos sobre a crise econômica do párs, ser sucedida por uma ampla cobertura do nascimento da filha da Xuxa ou ainda pelo heró́smo dos "amigos da escola". São os "fatos-ônibus", aqueles que não envolvem disputas, não dividem, interessam e satisfazem a todo mundo sem contudo tocar em nada de importante. Porém, não é a criação mediática do acontecimento que interessa ao historiador, mas nas palavras de Nora, "o duplo sistema que se entrecruza nele, sistema formal e sistema de significação; e ele se encontra mais bem colocado do que ninguém, para se apropriar desse sistema."

\footnotetext{
"NCRA, Pierre. O retorno do fato. In: LE (SOFF, Jacques; NORA, Pierre (Crg.). História: novos problemas. 2. ed. Rio de Janeiro: Francisco Alves, 1979. p. 180-181.

ithidem, p. 184.

"BOURDIEU, Pierre. Sobre a telenisäo. Rio de Janeiro: Zahar, 1997.

"N()RA, of. cit., p. 190.
} 
Uma apropriação que não pode em nenhum momento desconsiderar o fato de estarmos trabalhando com uma fonte que possui a particularidade estratégica do "efeito do real", ou seja, nas modernas sociedades de massas a TV é a que pode "fazer crer no que faz ver". Um verdadeiro processo de criação cultural e que enquanto tal, "deve ser aproximada das atividades políticas; e de fato, nesse sentido, pode-se falar de uma política cultural"10, que no caso da mídia é altamente socializadora, permeando a construção de toda uma concepção de mundo que os nossos alunos trazem para as salas de aula. En sentido amplo, essa formação visa a construção de sujeitos que na concepção gramsciana são denominados de homens-massa, ou seja, na formação de telespectadores com uma visão fragmentada e heterogênea de mundo, que os fazem protagonistas de uma cultura eminentemente "subalterna".

Gramsci argumenta que a cultura subalterna apesar de não representar uma produção autônoma, não se estrutura de forma passiva, simplesmente incorporando como seus, elementos extrínsicos à sua realidade, ou seja, elementos das frações dominantes. Na verdade, a cultura subalterna resulta de um constante processo de reelaboração de seus elementos constitutivos, sejam eles intrínsecos ou extrínsecos, chegando a mudar-lhes a forma e até mesmo o conteúdo. Porém, por ela não ser autônoma, não possui uma unidade crítica e por não ser organizada, acaba sempre por seguir uma determinada direção ideológica, que é a do grupo hegemônico. Em outras palavras, nossos educandos não são sujeitos passivos às informações televisivas, contudo, a falta de organicidade na crítica desses elementos ideológicos acaba sempre por ceder espaço à introjeção

"GRAMSCI, Antônio. A literatura e a vida nacional. Rio de Janeiro: Civilização Brasileira, 1978. p. 27.

"Idem. Comceptéto Dialética da História, p. 20. 
do discurso mediático. Essa organicidade necessária - apesar de fazer parte de um processo educativo mais amplo, que em última análise perpassa a construção de um projeto contrahegemonico da própria sociedade - pode ser em parte construída pelo mínimo de conhecimentos que se tenha da pedagogia mediática televisiva.

Nesse sentido, algumas questões valem a pena ser evidenciadas: a objetividade televisiva, a seleção/fragmentação) seletiva dos fatos, a identificação/projeção, a exploração da emotividade e o desenvolvimento da tecnologia.

Primeiramente, os acontecimentos chegam ao telespectador sob a marca da objetividude. Ora, a objetividade é exatamente o mais privilegiado instrumento de desconstrução da prática docente conscientizadora. Afinal, o verdadeiro educador é aquele capaz de mostrar ao educando que a relatividade da verdade the dá as chaves para sua própria interferência no mundo, uma interferência sem dúvida condicionada, ideológica, capaz de fazer com que ele transforme suas relações a partir de sua posição na materialidade histórica. Nas palavras de Gramsci, "toda ciência é ligada às necessidades, à vida, à atividade do homem. Sem a atividade do homem, criadora de todos os valores, inclusive os científicos, que seria a objetividade?" 12 A televisão pretensamente tenta responder a essa pergunta, passando para o público a "verdade" dentro de uma visão dita "neutra" dos fatos, negando seu caráter ideológico. A imagem que é veiculada e o discurso que é feito pelo apresentador, pelo ator, pelo artista, tornam-se a própria verdade incontestável do ocorrido, acabando por escamotear o âmbito ideológico. Não é raro encontrarmos argumentações como: "É verdade, deu no Jornal"ou"foi o Cid Moreira quem disse". Além do magnetismo audiovisual aperfeiçoado a cada dia pelas

:GRAMSCI, op. cit., p. 70. 
tecnologias, a instituição "TV", a emissora, o apresentador, o artista, ganharam uma idoneidade na construção da "verdade", capaz de fazer inveja aos historiadores positivistas do século XIX

Além disso, a TV mediatiza uma História sob as bases da fragmentação seletiva dos fatos, o que simplifica e esteriliza o conhecimento. A televisăo tornou-se a arte de se informar de tudo um pouco, para que ninguém seja efetivamente informado de nada. Essa fragmentação, ao perpassar uma seletiva "salada mista" de informaçoes, recria um "universal" que atomiza, banaliza as diferenças culturais, pasteurizando-as numa história sem conflitos.

Ora, numa educação transformadora, a construção das identidades participativas, dos sujeitos históricos, prima pelo conhecimento de uma totalidade capaz de permitir à parte reconhecer-se frente à materialidade econômica-social, dandolhe instrumentos de luta e de superação em relação à vida, ou seja, transformando organicamente sua forma de sentir, pensar e agir junto à realidade. A fragmentação seletiva associada a simplificações de conteúdo/pensamento, nos levam à questão da completa deteriorização nas veiculações, do sentido do processo histórico e de suas implicações econômicas e sociais. O processo ou ainda, a dialética histórica, acabam sendo suplantados pela personalização, onde "alguns sujeitos"passam a ser os agentes responsáveis pelos fatos, em sua maioria, os sujeitos privilegiados do mundo da política, que acabam viabilizando a máxima positivista da história dos grandes homens.

Em terceiro lugar, a TV utiliza-se do que muitos teóricos de comunicação chamam de efeito nurcisístico, ou seja, a identificação, a paixão por seu próprio reflexo. Em outras palavras, a imagem que seduz, é aquela que reflete o universo de quem a assiste. Mais do que isso, é a que reflete os desejos, as potencialidades na maioria das vezes, inconscientes do público. 
Em sociedades onde o apelo do "consumo pelo consumo" constitui um capital social altamente alienador e integrador, a veiculação pela mídia televisiva de determinados eventos ditos de "participação popular", tornaram-se antes de tudo, um espetáculo narcisístico. Muniz Sodré, exemplifica essa colocação quando abordou as manifestações populares norteamericanas pela desocupação da Ásia:

[...] já se davam de acordo com um modelo adaptado à difusão ou a reproxlutividade da mília: passeatas notáveis pela excentricidade das roupas, dos rostos, dos gestos. Era como se já fossem organizadas em função da exuberante transmissão televisiva. ${ }^{13}$

O que tivemos nesse caso, foi o espetáculo mediático se sobrepondo à problemática do imperialismo norte-americano no mundo. Descrição semelhante pode ser feita por exemplo, em relação aos "cara-pintada" na deposição do Collor. Mais importante que a implantação da política neoliberal no governo, foi pintar a cara, rasgar a roupa, e reviver comercialmente os "anos rebeldes". Ou seja, a transmissão dessa participação popular, foi esvicziada politicamente, tanto pelo apelo consumista, como pela criação de valores "participativos" superficiais e alienados. Contudo, o que fica para muitos telespectadores, é a ilusão de estar efetivamente participando, de ser um sujeito da História, uma vez que vê no outro que aparece na imagem, o reflexo ativo de seus próprios desejos, paixões, potencialidades. Diante da inércia de cada um, a televisão comercializa a ação, o comportamento, a experiência do vivido. Assim, ser um sujeito histórico pela visão nurcisística é antes de tudo, identificação e projeção ideologicamente direcionadas.

ISODRÉ, of. cit., p. 32. 
Outra questão que devemos levar em conta diz respeito ao apelo emotivo do cual a mídia televisiva se vale, uma verdadeira pedagogia dos sentimentos populares. Segundo Ferrés, a eficácia socializadora que as informações televisivas despertam, baseiam-se nas implicações emotivas que elas despertam: "se a televisão possui um caráter socializador, é sobretudo em função da enorme torrente de energia emotiva que gera" "'. Essas implicações emotivas envolvem uma complexa estrutura de identificação e de projeção (o efeito nurcisístico do qual falamos) yue não necessariamente se dão à nível racional. Segundo o autor, a televisão tende a agir no inconsciente, no reduto das emoções humanas - o que não quer dizer que as informações recebidas pelos telespectadores, não passem pela razão, mas sim, que são processadas dentro de uma dialética entre o emotivo e o racional, ou o inconsciente e o consciente, pensimento primário e secundário - sendo o objetivo da TV, fazer com que nesse processo, o apelo emotivo acabe por sobrepor-se ao pensamento racional.

Nesse sentido, as reportagens de extremo sensacionalismo que de estamos sendo vítimas nos últimos anos são capazes de levar o público das lágrimas à esteria sem contudo passar pelo plano da materialidade histórica real, que comporta as desigualdades e as lutas sociais.

Destacamos abaixo um trecho onde Ferrés nos elucida un pouco mais essa interação do narcisismo e da emoção, ençuanto armas pedagógicas utilizadas pela TV:

[...] Como as crianças frente aos contos, o espectador adulto participa emocionalmente nas narrativas, mediante os mecanismos psicológicos da identificação e da projeção. [...] A identificação e a projeção são dois mecanismos de transferência realizados com frequência de maneira inconsciente. Baseiam-se efetivamente,

"HERRÉS, Join. Televisão Subliminur: socializando através de comunicaçōes despercebidias. Porto Alegre: Artemed, 1998. p. 164. 
num processo de deslocamento que consiste em atribuir a realidades externas (situações ou personagens da ohra cinematográfica ou televisiva) as excitações internas, com o fim de superá-las, ou exercer algum tipo de controle ou de domínio sobre elas. [...] A emoção facilita o engano, dando maior peso de objetividade à aparência. $^{15}$

Enquanto na concepção de uma educação progressista, o afeto e a emoção são utilizados como forma de construção do conhecimento, da ação transformadora, a "educação televisiva" prima pela utilização do emotivo como forma de anestesiar a função crítica do indivíduo. Na primeira, a afetividade é a mola propulsora de uma educação dialética, na segunda, é a violência simbólica it que mascara um conhecimento unilateral.

Por fim, o avanço da tecnologia é fator inalienável da reconstrução mediática do real. A construção da mensagem televisiva passa pelo "uso" de técnicas que lhe são próprias, e nesse sentido, elas são partes integrantes e definidoras não só do "que se vê", mas obviamente do que se quer simbolicamente construir. A escollha dos ângulos de enquadramento de câmera, sua fixidez ou mobilidade, a escala da filmagem, a diferença de planos, são recursos que, se analisados do ponto de vista da frequência em que aparecem, podem nos fornecer dados importantes a respeito do conteúdo simbólico da mensagem. Portanto, a violência simbólica que a TV pratica sob o status de verdade, não está apenas no conteúdo dos discursos ou das imagens relacionadas aos fatos, mas também se encontra nas técnicas de

is Idem, ibidem, p. 96.

16. Com Bourdieu, entendemos que a violência simbólica diz respeito ao ocultamento do caráter ideológico, onde o individuo apesar de combecerl reconhecer-se a partir daquelas mensagens, ou ainda das representatividades simbólicas, as ignora enquanto poder (cf. BOURLIEU, Pierre. O poder simbólico. Rio de Janciro: Difel Editora, 1989). 
transmissão dos mesmos. Levar nossos alunos à reflexões de como são realizados os programas, os truques utilizados, a criação imagética de contextos, ajudam a desmistificar o meio, a distanciar-se dele através de uma reflexão mais madura. O que equivale a não simplesmente criticar o conteúdo televisivo, mas apreender e dominar os processos através dos quais aquele conteúdo é produzido.

Esses elementos juntos permeiam a construção de uma concepção de mundo amorfa, onde a simulação do vivido, com seu viés pronto e acabado toma cada vez mais o espaço da "verdadeira" realidade, ou a realidade não mediatizada. Ou seja, a televisão "dá", oferece a realidade, enquanto que uma educação transformadora deveria primar por uma "construção em conjunto" e à partir da experiência do vivido.

Diante destas questões, pode parecer que temos uma visão "apocalíptica" do meio televisivo, para usar a clássica divisão feita na década de 1960 por Umberto Eco, onde os "apocalípticos" viam na mídia uma ameaça intransponível para a cultura e a democracia, encuanto os "integrados" rejubilavam-se com a democratização do acesso de "milhões" a essa "cultura do lazer". ${ }^{17}$

Não ignoramos que a TV de certa forma, promove e contribui para a relação do indivíduo com a sociedade, mas sim que inegavelmente ela acaba, em contrapartida, por afastar esses mesmos indivíduos da cena pública, da materialidade histórica, ao reproduzir um espaço onde todos e ao mesmo tempo ninguém faz parte. Segundo Salogga, "tudo é feito para que o público espectador, convocado em casa através da televisão, vá, seja mais um elemento difuso e somente possa saber o que aconteceu no espetáculo em seu verdadeiro foco, a telinha." " Freire nos chama atenção de que "os homens se educam em

"Ver EC(), Umberto. Aproculípticos e Integrados. São Paulo: Difel, 1991. 
comunhão, mediatizados pelo mundo" ${ }^{\prime \prime}$, por outro, a TV toma cada vez mais o espaço dessa comunhão, através das experiências vicárias.

Considerações como estas ayui colocadas não esgotam a ampla dinâmica da hegemonia mediática junto a formação/ construção das concepções de mundo trazidas por nossos alunos, mas pode nos ajudar a desvendar de certa forma a pedagogia socializadora da televisão enquanto poder político e educativo em nossas sociedades.

Estarmos atentos para a hegemonia televisiva, é antes de tudo nos posicionarmos na luta contra-hegemônica em prol de uma História real, fruto de nossa participação ativa e consciente. É resgatarmos, junto aos nossos educandos, o princípio básico de uma cidadania concebida como unidade-plural dos anseios reais da coletividade, que só podem constituir-se em núcleos orgânicos de representatividade, a partir do momento em que nos organizarmos perante o vivido, saindo da inércia de nossas poltronas onde a "reconstrução" mediática da História pode nos abortar a ação.

\section{Referências Bibliográficas}

BOURDIEU, P. Sobre televisão. Rio de Janeiro: Zahar Editor, 1997.

. () Poder Simbólico. Rio de Janeiro: Difel, 1989.

ECO, U. Aproculípticos e Integrados. São Paulo: Difel, 1991.

"is SABOCA, Hério; FONTES, Virgínia. Escola, Televisão e Cidadania. In: À Margem: Revista de Ciências Humanas, Rio de Janeiro, ano III, n. 4, 1994. p. 49 .

"FREIRE, Paulo. Pedegogia do oprimido. 17. ed. Rio de Janeiro: Paz e Terra, 1987. . . 69 . 
FERRÉS, J. Televisäio Subliminar: socializundo atruvés de comunicações despercebidas. Porto Alegre: ARTMED, 1998.

FREIRE, P. Pedagogia do Oprimido. 17. ed. Rio de Janeiro: Paz e Terra, 1987.

GRAMSCI, A. Concepção Diulética da Históric. 10. ed. Rio de Janeiro: Civilizaç̧ão Brasileira, 1995.

GRAMSCI, Antônio. Literuturue vidu nuciomul. Rio de Janeiro: Civilização Brasileira, 1978.

IANNI, O. O Príncipe Eletrônico. Revista Primeira Versão, Campinas : IFCH/ UNICAMP, n. 78, 1998.

NORA, P. O retorno do fato: In: HISTÓRIA: novos problemas. 2. ed. Rio de Janeiro: Francisco Alves, 1979.

SABOGA, H.; FONTES, V. Escola, Televisão e Cidadania. À Murgem: Revista de Ciências Humanas, Rio de Janeiro, ano II, n. 4, 1994.

SODRÉ, M. O monopólio de fulu: função e linguagem da televisão no Brasil. Petrópolis: Vozes, 1977.

Vozes, 1986.

- Reimuentunde c culturu: a comunicação e seus produtos. Petrópolis:

SUMMARY:

To think the teaching of History today is, above all, the consideration of many ways to educate, many times much more socialized than the institutionalized teaching, as the case of the televised media. The present text is about the pedagogy of the televised media while powerful opinion former in the modern societies and about the conseyuences of this exercise of hegemony versus our students' formation, and to the construction of the historical knowledge.

KEY WORIDS: televised media, hegemony, History Teaching. 